Hydrol. Earth Syst. Sci., 17, 1985-2000, 2013

www.hydrol-earth-syst-sci.net/17/1985/2013/

doi:10.5194/hess-17-1985-2013

(C) Author(s) 2013. CC Attribution 3.0 License.

\title{
Analysis of long-term terrestrial water storage variations in the Yangtze River basin
}

\author{
Y. Huang ${ }^{1,2}$, M. S. Salama ${ }^{1}$, M. S. Krol ${ }^{2}$, R. van der Velde ${ }^{1}$, A. Y. Hoekstra ${ }^{2}$, Y. Zhou ${ }^{3}$, and Z. Su ${ }^{1}$ \\ ${ }^{1}$ Faculty of Geo-Information Science and Earth Observation (ITC), Department of Water Resources, University of Twente, \\ Enschede, the Netherlands \\ ${ }^{2}$ Faculty of Engineering Technology, Department of Water Engineering and Management (WEM), University of Twente, \\ Enschede, the Netherlands \\ ${ }^{3}$ State Key Lab of Estuarine and Coastal Research (SKLEC), East China Normal University, Shanghai, P.R. China
}

Correspondence to: Y. Huang (huang@itc.nl)

Received: 28 August 2012 - Published in Hydrol. Earth Syst. Sci. Discuss.: 5 October 2012

Revised: 18 March 2013 - Accepted: 11 April 2013 - Published: 27 May 2013

\begin{abstract}
In this study, we analyze $32 \mathrm{yr}$ of terrestrial water storage (TWS) data obtained from the Interim Reanalysis Data (ERA-Interim) and Noah model from the Global Land Data Assimilation System (GLDAS-Noah) for the period 1979 to 2010 . The accuracy of these datasets is validated using $26 \mathrm{yr}$ (1979-2004) of runoff data from the Yichang gauging station and comparing them with $32 \mathrm{yr}$ of independent precipitation data obtained from the Global Precipitation Climatology Centre Full Data Reanalysis Version 6 (GPCC) and NOAA's PRECipitation REConstruction over Land (PREC/L). Spatial and temporal analysis of the TWS data shows that TWS in the Yangtze River basin has decreased significantly since the year 1998. The driest period in the basin occurred between 2005 and 2010, and particularly in the middle and lower Yangtze reaches. The TWS figures changed abruptly to persistently high negative anomalies in the middle and lower Yangtze reaches in 2004. The year 2006 is identified as major inflection point, at which the system starts exhibiting a persistent decrease in TWS. Comparing these TWS trends with independent precipitation datasets shows that the recent decrease in TWS can be attributed mainly to a decrease in the amount of precipitation. Our findings are based on observations and modeling datasets and confirm previous results based on gauging station datasets.
\end{abstract}

\section{Introduction}

Terrestrial water storage (TWS) is determined by all physical phases of water stored above and below the surface of the Earth, including soil moisture, snow and ice, canopy water storage, groundwater, etc. As a key component of terrestrial and global hydrological cycles, TWS strongly influences water, energy, and biogeochemical fluxes, thereby playing a major role in the Earth's climate system (Famiglietti, 2004). TWS is not only an indicator of the Earth's climate variability, but also affects various components of the Earth's hydrological cycle (Niu et al., 2006). Soil moisture plays a key role in both the water and energy cycles through its impact on the energy partitioning at the surface, and soil moisture also has links with the biogeochemical cycle via plant transpiration and photosynthesis (Seneviratne et al., 2010). Snow cover has a strong influence on the onset of the summer monsoon and runoff production in spring (Ding et al., 2009). Therefore, the spatial and temporal variability in TWS due to climate change and human-induced impacts both form important components in the water and energy cycles, and should be taken into account in river basin management.

From a historical perspective, there is limited information about the TWS distribution in time and space, as TWS is not routinely assessed like other hydrometeorological measurements. Isolated datasets are available for only a few regions and rarely for periods of more than several years. Moreover, the in situ observations are point measurements, and 
not always representative for larger spatial domains (Famiglietti et al., 2008; van der Velde et al., 2008). Fortunately, progress in satellite remote sensing and corresponding retrieval techniques enables large scale monitoring of land surface bio-geophysical properties (e.g. soil moisture and temperature). This may potentially improve our understanding of the spatially heterogeneous hydrometeorological processes. Advances in microwave remote sensing have demonstrated their use in providing large-scale soil moisture information, resulting in satellite missions specifically dedicated to soil moisture (Entekhabi et al., 2010). Microwave observations can, however, only provide information on the top few centimeters of the soil. In addition, Tapley et al. (2004a,b) and others have shown that, using measurements of the Earth's gravity field, terrestrial water storage change (TWSC) may be inferred on a monthly scale. The first space mission that employs this technology is the Gravity Recovery and Climate Experiment (GRACE) launched on 17 March 2002.

Data assimilation products such as Interim Reanalysis Data (ERA-Interim) and Global Land Data Assimilation System (GLDAS) combine the virtues of in situ data, remotely sensed observations, and modeling. The models in these systems simulate the main components of TWS and, by fusing these components with other data sources, reduce uncertainties in the hydrological interpretations. These systems have been extensively applied in TWS and related studies, and have, for example, been utilized in regional, continental, and global TWS variation analysis (Chen et al., 2005; Seneviratne et al., 2004; Syed et al., 2008). As well, these systems offer long-term records of data, making them suitable for long-term analysis, while remotely sensed data and in situ observations are most likely time limited.

In this study, we focus on the analysis of the long-term variation in TWS of the Yangtze River basin. The Yangtze River, the longest river in China, forms one of the world's top ten rivers basins as far as water shortage is concerned. This shortage is caused by intensive human water use, and is despite the large volume of runoff the river basin receives (Wong et al., 2007). During the past three decades, the Yangtze River basin has experienced fundamental changes, e.g. a marked increase in temperature, population growth, economic development, water consumption, as well as the dam construction. The Three Gorges Dam (TGD) is the largest hydroelectric dam, and has created the largest manmade lake (more than $600 \mathrm{~km}^{2}$ of former land) in the world. Such sizeable land use changes alter many factors, such as albedo, regional climate, and the hydrological cycle. In recent years, the basin has experienced an increasing trend in the frequency of extreme events, i.e. low runoff in drought years, and floods during intense rainfall (Dai et al., 2008; IPCC, 2001). A better understanding of the changes occurring in the Yangtze River basin and its hydrological state variables is thus important. However, previous work has mostly focused on the interaction between runoff, precipitation, and evapotranspiration in the basin, while little attention has been paid to space-time variability in TWS and its response to climate change and human activity.

In this paper, we examine the spatial and temporal variation in TWS in the Yangtze River basin, with the aim to improve our understanding of the water cycle and aid management of the water resources. The specific objectives of this paper are (1) to use an ERA-Interim dataset to estimate the TWS and TWSC for the period 1979 to 2010, (2) to assess the accuracy of the TWS estimation from ERA-Interim and GLDAS datasets in the basin, (3) to examine the climatology of the spatial pattern of TWS in the basin, and (4) to detect trends and abrupt changes, as well as their possible causes.

\section{Study area}

The Yangtze River basin is located in the subtropical zone in China. The river originates in the Qinghai-Tibetan Plateau and flows $6300 \mathrm{~km}$ eastwards to the sea. The upper Yangtze reaches, the headwaters, extend from the westernmost point, at Tuotuohe, to Yichang. The middle reaches extend from Yichang to Hukou, and the lower reaches extend from Hukou to the river mouth near Shanghai (Fig. 1). Cuntan forms the entrance to the Three Gorges Dam (TGD), which extends more than $600 \mathrm{~km}$ along the mainstream of the Yangtze River. The Three Gorges Dam was constructed $37 \mathrm{~km}$ upstream from Yichang for multiple purposes: energy generation, flood control, and water supply.

\section{Datasets}

\subsection{ERA-Interim}

The ERA-Interim reanalysis dataset contains physical data of atmosphere and surface analyses covering the period from 1979 to the present based on the ECMWF Integrated Forecast System (IFS) release Cy31r2 (Berrisford et al., 2011; Simmons et al., 2006). The reanalysis incorporates a forecast model with three fully coupled components for atmosphere, land surface and ocean waves, and assimilates various types of observations, including satellite and ground based measurements. It uses the Tiled ECMWF Scheme for Surface Exchanges over Land (Viterbo et al., 1995) to simulate heat and water exchanges between land and atmosphere. The TESSEL model structure includes four soil layers (0$7,7-28,28-100$, and $100-289 \mathrm{~cm}$ ) for each type of vegetation scheme and each type of snow scheme. As the latest global atmospheric reanalysis produced by ECMWF, it has been confirmed that the performance of this system is substantially improved in certain key aspects (the representation of the hydrological cycle, the quality of the stratospheric circulation, and the consistency in time of the reanalyzed fields) compared to EAR-40 (Dee et al., 2011).

The monthly means, based on daily means of volumetric soil water in the four layers, as well as snow depth and 


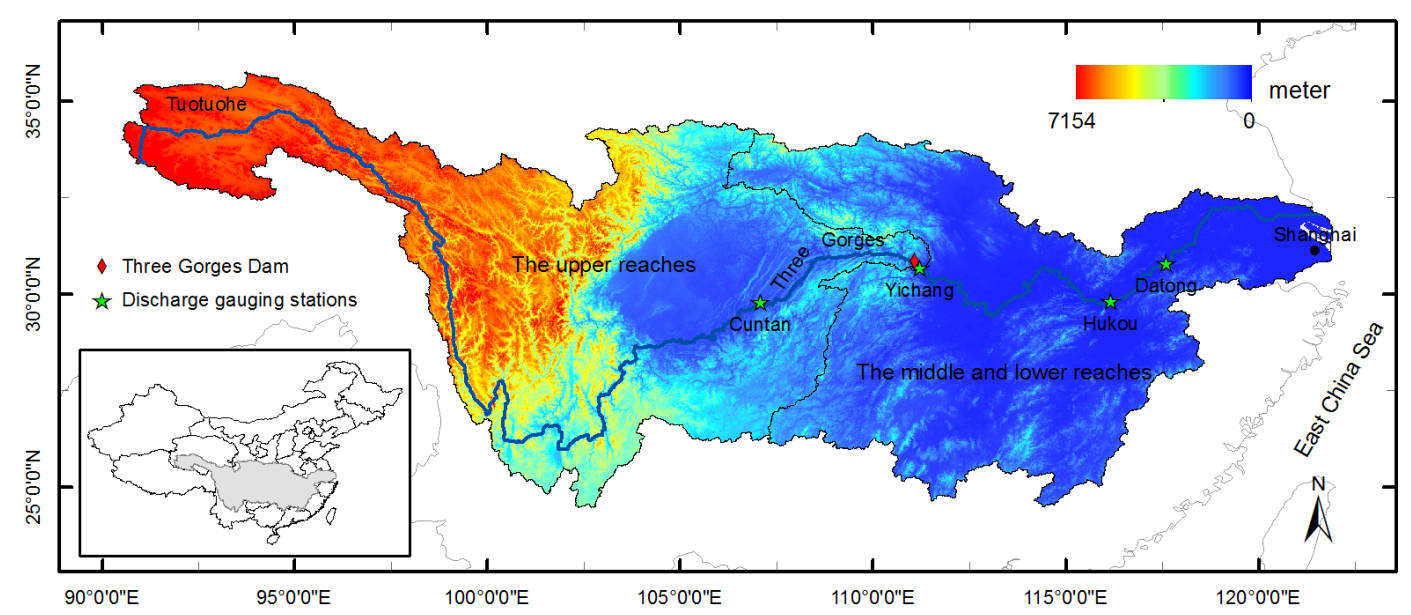

Fig. 1. Elevation map of the study area, the Yangtze River basin. The green stars denote the locations of the main gauging stations. The position of the Three Gorges Dam is depicted by a red diamond.

snow density, with a spatial resolution of $1.5^{\circ}$, and collected in the period January 1979 to December 2010, are used in this study (available on http://data-portal.ecmwf.int/data/d/ interim_moda/).

\subsection{GLDAS-Noah}

The Global Land Data Assimilation System (GLDAS) supplies users with a model output of state-of-the-art land surface schemes created with atmospheric variables that originate from various data sources. The model has been forced by multiple datasets: bias-corrected ECMWF Reanalysis data for the time period 1979 to 1993, bias-corrected National Center for Atmospheric Research (NCAR) Reanalysis data for 1994 to 1999, NOAA/GDAS atmospheric analysis fields for 2000 and a combination of NOAA/GDAS atmospheric analysis fields, spatially and temporally disaggregated NOAA Climate Prediction Center Merged Analysis of Precipitation (CMAP) fields, and observation-based downward shortwave and longwave radiation fields, using the method of the Air Force Weather Agency's AGRicultural METeorological modeling system (AGRMET), for the period 2001 to the present (Rui, 2011).

In this study, we use the model output produced by the Noah land surface scheme. These data are available from 1979 to the present at $3 \mathrm{~h}$ intervals. The Noah soil moisture profile includes four layers, namely $10,30,60$, and $100 \mathrm{~cm}$, from the soil surface down. The monthly products generated through temporal averaging of the $3 \mathrm{~h}$ interval products of soil moisture content (SMC) and snow water equivalent (SWE) during the period January 1979 to December 2010 are used in this study. Data generated by the GLDAS-Noah is publicly available on http://ldas.gsfc.nasa.gov/gldas/.

\subsection{Field data}

The monthly river discharge at the Yichang Gauging Station (Fig. 1) has been recorded over the period January 1979 to December 2004. This dataset is used to validate the ERAInterim land GLDAS-Noah outputs for the Yangtze River basin.

\subsection{GPCC}

The Global Precipitation Climatology Centre (GPCC) offers gauge-based, gridded, monthly precipitation datasets for the global land surface from 1901 to 2010. The GPCC Full Data Reanalysis Version 6 with a spatial resolution of $1.0^{\circ}$, which is fully independent of the precipitation data from ERAInterim and GLDAS-Noah, is used in this study. It uses the complete GPCC station database (ca. 67200 stations with at least $10 \mathrm{yr}$ of data) available at the time of analysis and is therefore recommended for use in global and regional water balance studies, the calibration/validation of remote sensing based rainfall estimations, and the verification of numerical models (Schneider et al., 2011).

\subsection{PREC/L}

NOAA's PRECipitation REConstruction over Land (PREC/L), a further gauge-based dataset regarding monthly precipitation over land (Chen et al., 2002), is included in this study (spatial resolution of $2.5^{\circ}$ ). PREC/L is based on different collections of gauge data than are used for the GPCC, and draws on a large number of stations until the 1990s. It has been documented by Wang et al. (2008) to have a very high anomaly correlation coefficient (root mean square error) with the observation. 


\subsection{GRACE}

GRACE RL05 level-3 land (L3-land) products from January 2004 to December 2010 are proffered by the Center for Space Research (CSR) at the University of Texas (available at ftp://podaac-ftp.jpl.nasa.gov/allData/tellus/L3/ land_mass/RL05/). Several tests (Bettadpur et al., 2012a,b) have proved that RL05 is more accurate than previously released GRACE products. The RL05 L3-land data are based on the RL05 spherical harmonics from the CSR, the Jet Propulsion Laboratory (JPL) and the German Research Centre for Geosciences (GFZ), and have additional, post processing steps, summarized on http:/grace.jpl.nasa.gov/data/ gracemonthlymassgridsland/.

\section{Methods}

\subsection{Water storage estimation}

TWS is generally defined as all phases of water stored above and below the surface of the Earth: soil moisture, canopy water storage, snow water equivalent and ground water, surface water storage, etc. Our analysis of storage is, however, limited to the total soil moisture column (TSM) and snow water equivalent (SWE) and does not give a complete description of the lateral and vertical distribution of water storage unless surface and groundwater components are added to the land model used here. We also neglect canopy water storage (CWS), although this is included in the GLDAS-Noah simulation. The reason is that CWS in the Yangtze River basin is negligible in comparison with soil moisture (Zhong et al., 2010). Therefore, TWS is expressed as Eq. (1), where $N$ is an index representing the month of the year.

$\mathrm{TWS}_{N}=\mathrm{TSM}_{N}+\mathrm{SWE}_{N}$

The monthly change in terrestrial water storage $\left(\mathrm{TWSC}_{N}\right)$ can be calculated at each pixel as follows:

$\mathrm{TWSC}_{N}=\left\{\mathrm{TSM}_{N}+\mathrm{SWE}_{N}\right\}-\left\{\mathrm{TSM}_{N-1}+\mathrm{SWE}_{N-1}\right\}$

This method elicits promising results and also compares well with the Gravity Recovery and Climate Experiment (GRACE) estimation and the monthly basin-scale terrestrial water balance approach from flux variables (Chen et al., 2009; Rodell et al., 2004; Syed et al., 2008). The ERAInterim soil profile includes four layers of 7, 21, 72, and $189 \mathrm{~cm}$ depth (forming a total of $289 \mathrm{~cm}$ ), while the Noah soil profile includes four layers of $10,30,60$, and $100 \mathrm{~cm}$ $(200 \mathrm{~cm}$ in total). In order to be able to compare the TWS information obtained from both these datasets, we only considered the first $200 \mathrm{~cm}$ of soil in both cases.

\subsection{Statistical analysis}

Trend analyses involve linear regression and the nonparametric Mann-Kendall (MK) test (Mann, 1945; Kendall,
1975). A linear regression model is used to compute the annual trend in the TWS for each pixel. The MK test is a rankbased procedure and is applied to detect the significance of the trends. The MK test statistics are given by

$Z=\left(\begin{array}{cr}(s-1) / \sigma & S>0 \\ 0 & \text { if } S=0 \\ (s+1) / \sigma & S<0\end{array}\right)$

where

$s=\sum_{i=1}^{n-1} \sum_{j=i-1}^{n} \operatorname{Sgn}\left(X_{j}-X_{i}\right)$

and

$\operatorname{Sgn}\left(X_{j}-X_{i}\right)=\left(\begin{array}{cc}+1 & X_{j}-X_{i}>0 \\ 0 & \text { if } X_{j}-X_{i}=0 \\ -1 & X_{j}-X_{i}<0\end{array}\right)$.

The $\sigma$ term is given by

$\sqrt{1 / 18\left(n(n-1)(n-5)-\sum_{t} t(t-1)(2 t+5)\right)}$

and $X_{j}$ and $X_{i}$ are the sequential data values, $n$ is the dataset record length, $t$ is the extent of any given tie (the number of annual maxima in a given tie), and $\sum$ is the summation of all ties. Positive and negative values of $Z$ indicate increasing and decreasing trends, respectively. The statistic $Z$ follows a normal distribution $N(0,1)$ (Burn and Hag Elnur, 2002; Yang et al., 2010). To analyze whether the trend is stationary in the TWS anomalies, the Mann-Kendall-Sneyers (MKS) test (Sneyers, 1975) is also applied. This test, a sequential version of the MK test, enables not only detection of significant trends, but also approximation of the transition point in the temporal behavior of a series. Let $x_{1}, \ldots, x_{n}$ be the data points. For each element $x_{i}$, the number $n_{i}$ of element $x_{j}$ preceeds it $(j<i)$ such that $x_{j}<x_{i}$ is computed. Under the null hypothesis (no trend), the test statistic $t_{k}=\sum_{i=1}^{k} n_{i}$ is normally distributed, with the mean and variance given by

$\overline{t_{k}}=E\left(t_{k}\right)=\frac{k^{2}-k}{4}$

$\bar{\sigma} t_{k}^{2}=\operatorname{var}\left(t_{k}\right)=\frac{k(k-1)(2 k+5)}{72}$.

Let $\mathrm{UF}_{k}=\left(t_{k}-\bar{t}_{k}\right) /\left(\bar{\sigma} t_{k}^{2}\right)^{(1 / 2)}$ be the normalized variable, which is the forward sequence. This principle can be usefully extended to the backward sequence $\mathrm{UB}_{k}$, which is calculated using the same equation but with a reversed series of data. When points in the forward series are outside the confidence interval, this indicates the detection of a significantly increasing $(\mathrm{UF}>0)$ or a significantly decreasing $(\mathrm{UF}<0)$ trend. If an intersection occurs between UF and UB within the confidence interval, this indicates an inflection (Li et al., 2004, 2007; Moraes et al., 1998). 


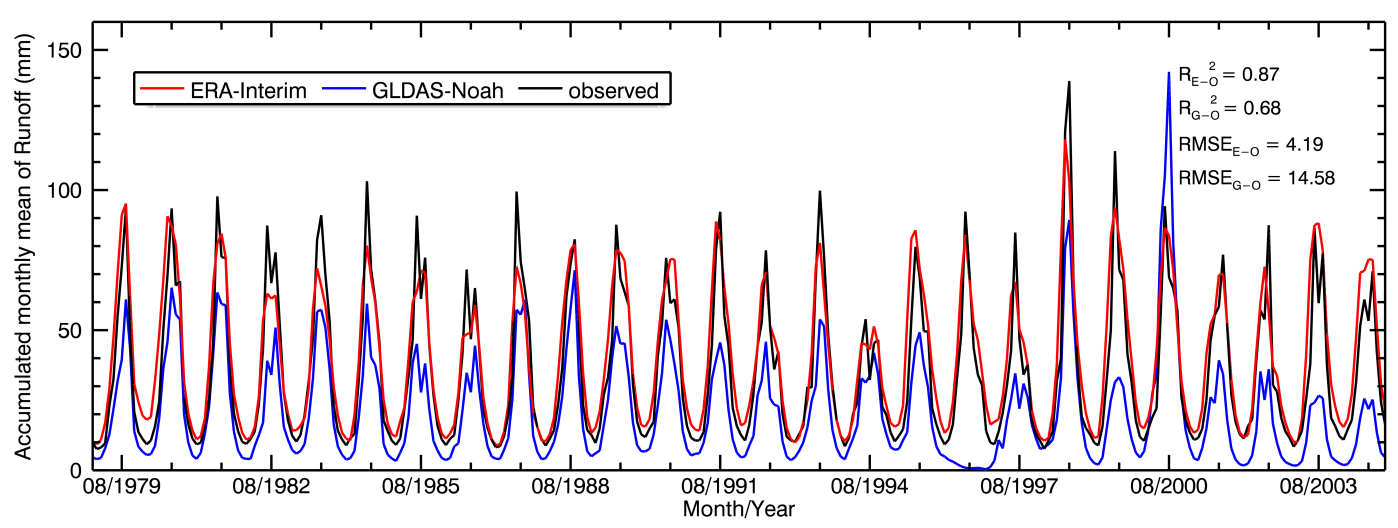

Fig. 2. Spatial averaged time series of ERA-Interim estimated (red curve), GLDAS-Noah estimated (blue curve) and observed (black curve) runoff of the upper Yangtze reaches between January 1979 and December 2004.

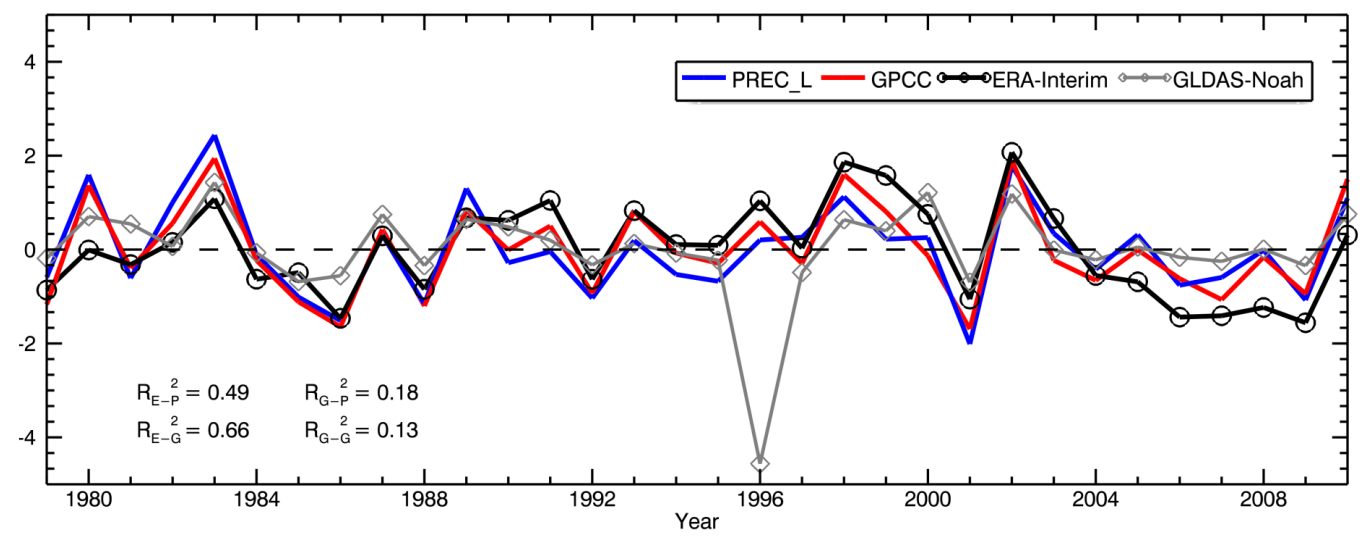

Fig. 3. Spatially averaged time series of standardized anomalies of the annual precipitation in the middle and lower Yangtze reaches, based on PREC/L (blue curve), GPCC (red curve), ERA-Interim (black circle curve) and GLDAS-Noah (gray diamond curve) data from 1979 to 2010 .

\section{Results and discussion}

\subsection{Evaluation and validation}

The regional accuracies and reliabilities of the ERA-Interim and GLDAS-Noah datasets are assessed by comparing their spatially averaged time series of runoff for the upper Yangtze River, generated by the observed discharge at the Yichang gauging station for the period 1979 to 2004. This procedure is based on the method of Balsamo et al. (2009) and is implemented in our study as follows:

a. ERA-Interim/GLDAS-Noah. Firstly, we computed the accumulated monthly runoff from ERAInterim/GLDAS-Noah data at each pixel during the period 1979 to 2004. Secondly, we calculated the spatial-mean of the accumulated monthly runoff $(\mathrm{mm})$ of all pixels located in the upper reaches of the Yangtze basin. b. Discharge at the Yichang gauging station. Firstly, we computed the accumulated monthly discharge $\left(\mathrm{m}^{3}\right)$ from the daily discharge data $\left(\mathrm{m}^{3} \mathrm{~s}^{-1}\right)$ of the Yichang station. Secondly, we divided this figure by the area of the upper Yangtze reaches. The second step is supported by the fact that the Yichang station forms the exit point of the upper reaches of the Yangtze River basin.

Figure 2 shows that the ERA-Interim modeled runoff fits the observed values better than the GLDAS-Noah modeled runoff does, for the period between 1979 and 2004. The coefficient of determination (R-squared) and the root mean square error (RMSE) between the modeled and observed values for ERA-Interim $\left(R_{\mathrm{E}-\mathrm{O}}^{2}, \mathrm{RMSE}_{\mathrm{E}-\mathrm{O}}\right)$ are 0.87 and $4.19 \mathrm{~mm}$, respectively, while for GLDAS-Noah $\left(R_{\mathrm{G}-\mathrm{O}}^{2}\right.$, $\left.\mathrm{RMSE}_{\mathrm{G}-\mathrm{O}}\right)$, they are 0.68 and $14.58 \mathrm{~mm}$, respectively. Note that the runoff is consistently underestimated by GLDASNoah, which is also confirmed by Zaitchik et al. (2010). GLDAS-Noah outputs show errors in 1996 and 1997. Apparently, ERA-Interim datasets show higher accuracy and reliability for the Yangtze River basin. 
To explore the quality of these datasets further and as precipitation arguably forms the most critical input into an accurate TWS, precipitation estimates of ERA-Interim and GLDAS-Noah are compared with products from the GPCC and PREC/L, which are derived more directly from observations. The spatially averaged time series of standardized annual anomalies have been computed and compared for these four datasets. The result (see Fig. 3) shows a notable error in 1996 concerning GLDAS-Noah. GPCC and PREC/L fit very well (their R-squared value is 0.86 ). Generally speaking, ERA-Interim precipitation fits PREC/L and GPCC better than GLDAS-Noah does. The R-squared between ERAInterim and PREC/L $\left(R_{\mathrm{E}-\mathrm{P}}^{2}\right)$ and between ERA-Interim and $\operatorname{GPCC}\left(R_{\mathrm{E}-\mathrm{G}}^{2}\right)$ are 0.49 and 0.66 , respectively, while the Rsquared between GLDAS-Noah and PREC/L $\left(R_{\mathrm{G}-\mathrm{P}}^{2}\right)$ and between GLDAS-Noah and GPCC $\left(R_{\mathrm{G}-\mathrm{G}}^{2}\right)$ are 0.18 and 0.13 , respectively. ERA-Interim generally shows good agreement with GPCC and PREC/L; however, a small shift has become apparent in the past decade, which we will discuss later.

In situ measurements of soil moisture are invaluable for the calibration and validation of a land surface model and satellite-based soil moisture retrieval. Unfortunately, there is a very low sampling rate with only 1 sample being available in the Yangtze River basin from the International Soil Moisture Network (ISMN) (Dorigo et al., 2011). However, the error structures of the ERA-Interim and GLDAS-Noah soil moisture products have been estimated using the triple collocation technique by Dorigo et al. (2010) and Scipal et al. (2008). ERA-Interim reanalyzed soil moisture is characterized by a relatively low mean global error of $0.018 \mathrm{~m}^{3} \mathrm{~m}^{-3}$ (Dorigo et al., 2010), which is fairly consistent with the average error (a mean global error of $0.020 \mathrm{~m}^{3} \mathrm{~m}^{-3}$ ) obtained by Scipal et al. (2008) by applying the triple collocation model to three satellite-based and model-based soil moisture products. It is found that the errors of soil moisture estimates in the Yangtze River basin are at an intermediate level. This can also be confirmed by the high correlation with ASCAT retrievals for the years 2007 and 2008 (Dorigo et al., 2010) and ERS-2 retrievals for the years 1998, 1999, and 2000 (Scipal et al., 2008). In addition, Liu et al. (2011) has shown that there is a high correlation coefficient $(R)$ between GLDAS-Noah and ASCAT retrievals for the Yangtze River basin in 2007. It has been firmly proven that active microwave satellite-based (e.g. ASCAT) retrievals result in smaller errors in moderately to densely vegetated areas (e.g. the Yangtze River basin) than passive microwave products do (Liu et al., 2011). Therefore, the high correlation between ERA-Interim, or GLDAS-Noah, and active microwave satellite-based soil moisture retrievals provides some confidence in the EAR-Interim and GLDAS-Noah soil moisture qualities in the Yangtze River basin.

Other components such as surface water and groundwater form a large proportion of the TWS. To assess their impact on the matchup, we compared TWS products derived from ERA-Interim to those derived from GRACE observations (reprocessed Release-05, GRACE RL05) for a sevenyear period (2004-2010). Figure 4 shows that the magnitude of the spatially averaged TWS anomalies from these two datasets (ERA-Interim and GRACE RL05) is similar and exhibits the same variation, with a coefficient of determination as high as 0.79 . This means that the ERA-Interim product on TWS over a soil depth of $2 \mathrm{~m}$ is representative for the GRACE observations that are affected by water storage fluctuations in the entire air-land column, including surface water and groundwater.

\subsection{Climatology}

Annual standardized anomalies are calculated by using the monthly values subtracted with the annual mean and divided by the annual standard deviation of the annual mean, which can be expressed as follows:

$A_{i j}=\frac{\left(\mathrm{TWS}_{i j}-\overline{\mathrm{TWS}_{j}}\right)}{\sigma_{j}}$

with

$\overline{\mathrm{TWS}_{j}}=1 / 12 \sum_{i=1}^{12} \mathrm{TWS}_{i j}$
$\sigma_{j}=\left(1 / 12 \sum_{i=1}^{12}\left(\mathrm{TWS}_{i j}-\overline{\mathrm{TWS}_{j}}\right)^{2}\right)^{1 / 2}$,

where $A_{i j}$ is the annual TWS standardized anomaly in the $i$ th month of the $j$ th year, TWS $i j$ is the TWS in the $i$ th month of the $j$ th year, $\overline{\mathrm{TWS}_{j}}$ is the mean TWS of the all months in the $j$ th year, and $\sigma_{j}$ is the standardized deviation of all months in the $j$ th year.

The spatial distribution of TWS and TWSC climatological annual standardized anomalies derived from ERA-Interim and GLDAS-Noah are shown in Figs. 5 and 6, respectively. The performance of ERA-Interim and GLDAS-Noah elicits large variability, to a large extent due to insufficient physical descriptions of land-surface processes (Niu et al., 2006; Zeng et al., 2008). Nevertheless, the spatial patterns reveal strong consistencies.

After suffering the dry season (December-February), the southeast corner of the Yangtze basin starts to become wet during March to May, due mainly to the south China rainfall belt extension and the mean precipitation increase in the lower basin (Ding and Chan, 2005; Qian et al., 2002). High, positive TWS standardized anomalies emerge in most of the Yangtze basin during June to October (Fig. 5), and show a large increase in July compared to June (Fig. 6), corresponding with the intensive precipitation observed along the whole Yangtze River from mid-June to mid-July (Ding, 1992), called the Meiyu in China. It is noted that negative TWS standardized anomalies still exist in the central area 


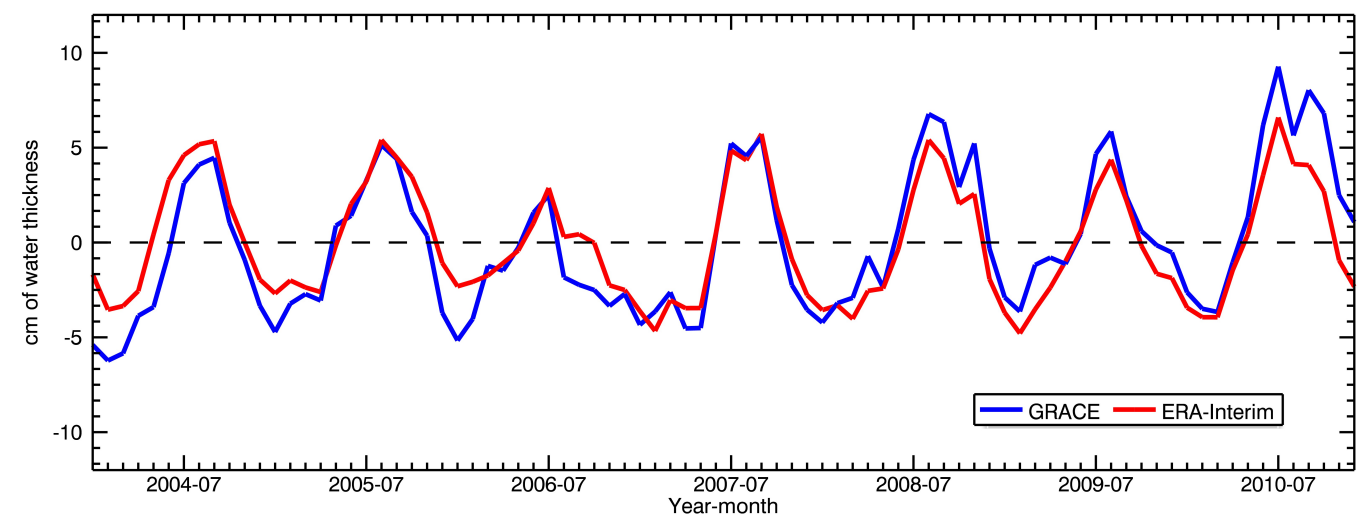

Fig. 4. TWS anomalies [cm] averaged for a seven-year period (2004-2010) and obtained from ERA-Interim (red line) and GRACE RL05 (blue line) datasets for the Yangtze River basin.

(around $107^{\circ} \mathrm{E}$ ) for ERA-Interim, which is different from the negative GLDAS-Noah value in the upper area. According to the climatological rainfall differences between May and June and between June and July (Qian et al., 2002, Fig. 4), the increased rainfall in June compared to May appears in the Plateau and in southwest China, with the center lying in the upper Yangtze reaches.

Another area of increased rainfall is located along the eastern coastland with its center in the lower Yangtze reaches. There is no obvious increase in rainfall in the central part of China. In July, the increased rainfall has migrated to the north of the lower Yangtze River basin, while rainfall is steadily increasing in the upper parts. This pattern of change in precipitation from May to July resembles the TWS pattern derived from ERA-Interim (Fig. 5). After July, the TWS anomalies in the middle and lower Yangtze reaches decrease sharply, while they stay quite high and positive in the upper Yangtze reaches till October, mainly due to the continuous rainy season from mid-June to mid-September.

This striking consistency between TWS and the rainfall pattern is not unexpected. That higher precipitation leads to higher soil moisture can generally be considered predictable, though there are a few exceptions. For instance, in the case of intense precipitation with rates beyond the infiltration rate, or precipitation over very wet or saturated areas, the rainfall anomalies will result in runoff anomalies rather than soil moisture (Dunne, 1978; Horton et al., 1933). Nevertheless, except in the extreme cases, there is an obvious and direct response of soil moisture to precipitation. On the other hand, the feedback, via the return path from soil moisture through evapotranspiration to precipitation, can also play an important role in the TWS variability, though a weaker one (Seneviratne et al., 2010). Abundant previous research (Dirmeyer, 2011; Jung et al., 2010; Wei et al., 2012) shows that the Yangtze River basin is dominated by wet soil moisture regimes, where soil moisture does not mainly control the variability in evapotranspiration and has only a minor impact on the change in rainfall. Dirmeyer (2011) also con- firms that soil moisture neither typically provides feedback to the atmosphere nor has a damping effect on climate variability. Thus, it is reasonable to speculate that the TWS variability in the Yangtze River basin is mainly controlled by large-scale atmospheric circulations, as is also established by Wei et al. (2012). Moreover, as displayed in Fig. 5, the Yangtze River basin suffered the highest TWS anomalies during June-July, which implies a high flood risk during this period, since runoff is sensitive to soil moisture content under wet soil regimes. When soil moisture is very high and soil becomes saturated, high precipitation variability may lead to high runoff variability, which cannot be damped by soil moisture storage (Seneviratne et al., 2010).

It should be recognized that the TWS pattern in the upper Yangtze reaches is completely different from that in the middle and lower Yangtze reaches, which may be explained by large-scale circulation and heterogeneous land-surface conditions. The upper Yangtze reaches are mainly influenced by the South Asian (or Indian) summer monsoon, and the middle and lower Yangtze reaches are controlled by the East Asian summer monsoon (Ding and Chan, 2005). The seasonal process of the Asian summer monsoon plays a crucial role in heat and moisture transport and the hydrological cycle. Related rainfall systems perform differently in the upper reaches than in the middle and lower reaches (Qian et al., 2002). Since the topography in the upper Yangtze reaches is totally different from that in the middle and lower reaches (Fig. 1), land-surface heterogeneities in temperature are expected (Giorgi et al., 1997; Salama et al., 2012). The land cover and hydrological conditions differ in the two areas (Piao et al., 2010). The inhomogeneous surface results in heterogeneity in surface energy partitioning, which in turn has an impact on land-atmosphere interactions (Brunsell et al., 2011; Ma et al., 2008). Therefore, different responses are expected by land-surface systems in the upper Yangtze reaches than in the middle/lower reaches. For example, soil moisture exerts a significant positive control on the maximum and mean temperature in the middle/lower reaches during 
summer, while no significant control is elicited in the upper reaches. Furthermore, while soil moisture and precipitation are positively coupled in the upper Yangtze reaches, this coupling is negative for the middle and lower Yangtze reaches (Zhang et al., 2011).

\subsection{TWS trend analysis}

Jung et al. (2010) pointed out that the major El Nino event in 1998 was followed by changes in the behavior of some land water cycle components, such as the SMC. Additionally, GLDAS-Noah outputs show errors in 1996 and 1997. Therefore, we only show the results of the ERA-Interim dataset and separate the whole study period into two parts, from January 1979 to December 1997, and from January 1998 to December 2010. In Fig. 7, the ERA-Interim dataset shows decreasing TWS trends over large parts of the Yangtze River basin between 1998 and 2010, which match the descending trend in the SMC from microwave satellite observations between 1998 to 2008 (Jung et al., 2010). It shows significantly decreasing trends (most of which surpass the $95 \%$, while some even surpass the $99 \%$ confidence level) in the middle and lower reaches, with a maximum of $-3.93 \mathrm{~mm} \mathrm{yr}^{-1}$. The upper reaches suffer milder decreases and even insignificant trends in some parts during the period 1998 to 2010. Between 1979 and 1997, it provides insignificant trends for most regions of the basin. This result indicates that the Yangtze River basin is drying up, the conclusion also reached by a new WWF study (http://www.asianscientist.com/topnews/ yangtze-river-basin-is-drying-up-wwf-china-2012/).

Monthly standardized anomalies of the TWS are calculated by the monthly TWS minus the corresponding monthly value of the annual cycle, and then divided by the standard deviation of the values of the same months within the period 1979 to 2010, in order to eliminate the influence of interannual variability for intra-annual analysis. Monthly standardized anomalies of the TWS can be expressed as follows:

$M_{i j}=\frac{\left(\mathrm{TWS}_{i j}-\overline{\mathrm{TWS}_{i}}\right)}{\sigma_{i}}$

with

$\overline{\mathrm{TWS}_{i}}=1 / 32 \sum_{j=1979}^{2010} \mathrm{TWS}_{i j}$

$\sigma_{i}=\left(1 / 32 \sum_{j=1979}^{2010}\left(\mathrm{TWS}_{i j}-\overline{\mathrm{TWS}_{i}}\right)^{2}\right)^{1 / 2}$

where $M_{i j}$ is the monthly TWS standardized anomaly in the $i$ th month of the $j$ th year. The subscripts $i$ and $\mathrm{j}$ represent the $i$ th month and $j$ th year, respectively; $\overline{\mathrm{TWS}_{i}}$ is the TWS of the $i$ th month averaged over all the years; $\sigma_{i}$ is the standardized deviation of $i$ th month TWS over all the years.
As discussed before, the ERA-Interim dataset has better accuracy, at least in the upper reaches of the Yangtze River, while GLDAS-Noah outputs show notable errors in 1996 and 1998. Therefore, only the ERA-Interim dataset is used in this section.

The MKS test is applied to detect the transition points in the temporal behavior of TWS standardized anomalies based on the annual mean, the wet season mean and the dry season mean, respectively. The definition of wet season and dry season is based on the precipitation climatology of the Yangtze River basin. The Yangtze River basin experiences a distinct wet season from about May to late September or early October. The corresponding dry season spans from late September or early October to spring. The summer monsoons contribute most of the wet season precipitation (Harvey et al., 2007). As seen in Fig. 8, generally speaking, the spatially averaged TWS standardized anomaly trends are not significant $(<95 \%$ confidence level) and not monotonic (i.e. with a transition point) during the period 1979 to 2010 . The only transition point during the $32 \mathrm{yr}$ period of 1979 to 2010, at which point the TWS standardized anomalies began to decrease sharply, occurred in 2006. This trend reaches the $95 \%$ confidence level in 2010. The transition point occurs one year earlier in the wet season, and two years later in the dry season. In the middle and lower Yangtze reaches, the transition point occurs around 2005 both in the wet and in the dry season. It is noted that there is a significant downward trend in 2009 and 2010 after four years of insignificant decrease. It was the first time this happened since the start of the study in 1979. In the upper Yangtze reaches, the TWS standardized anomalies experience mainly downward trends during the wet seasons of the past 3 decades and increasing trends during the dry seasons. In addition, transition points occur several times $(1982,1989,1995,2001,2005, \ldots)$ and in the period of 1986-1988, the decrease is significant in the wet season in the upper Yangtze reaches. We also examined the transition points through MKS of the TWS standardized anomalies in the middle and lower Yangtze reaches during June-July, and the result is exactly the same as in the wet season, though the TWS standardized anomalies do differ from each other.

As seen in Figs. 8 and 9, the past 6 yr period (2005-2010) was the driest period in the Yangtze River basin (especially in the middle and lower reaches) since 1979. This result is quite consistent with the severe drought events documented for the basin by other research. Wei et al. (2012) documented that the Yangtze River basin suffered one of the driest rainy seasons during the $32 \mathrm{yr}$ period of 1979 to 2010 in 2005, and Yan et al. (2007) noted that a widespread drought occurred over the southwestern part of the basin that same spring, and that it was the most serious drought since 1979 till 2007. Then the worst drought in more than a century struck southwest China and Sichuan in the summer of 2006, and Dai et al. (2008) showed that the middle and lower Yangtze River reaches suffered the lowest level of the past $50 \mathrm{yr}$ during that 

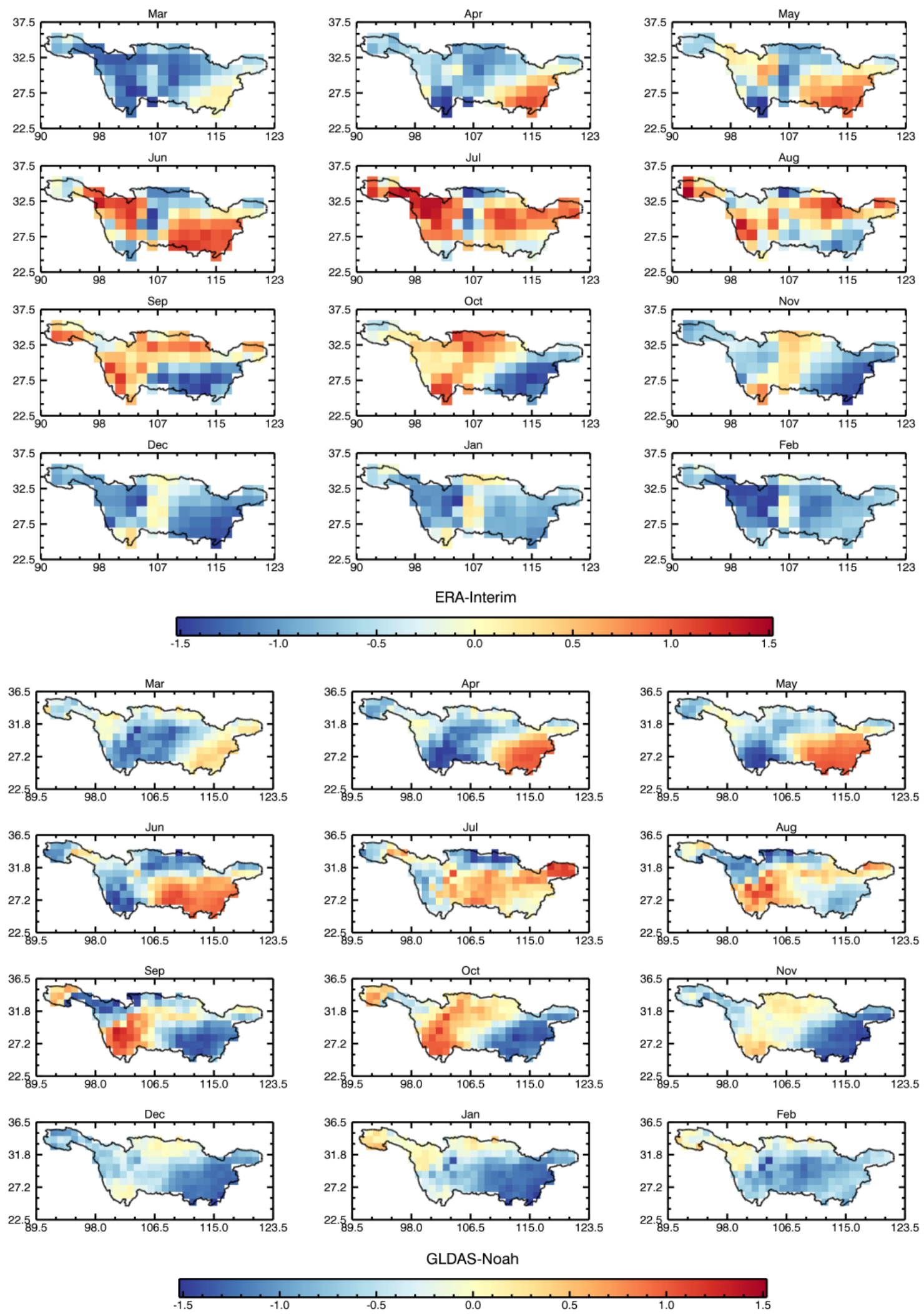

Fig. 5. Spatial patterns of monthly averaged TWS annual standardized anomalies computed from ERA-Interim for the period January 1979 till December 2010 and from GLDAS-Noah for the periods January 1979 till December 1995 and January 1998 till December 2010. 

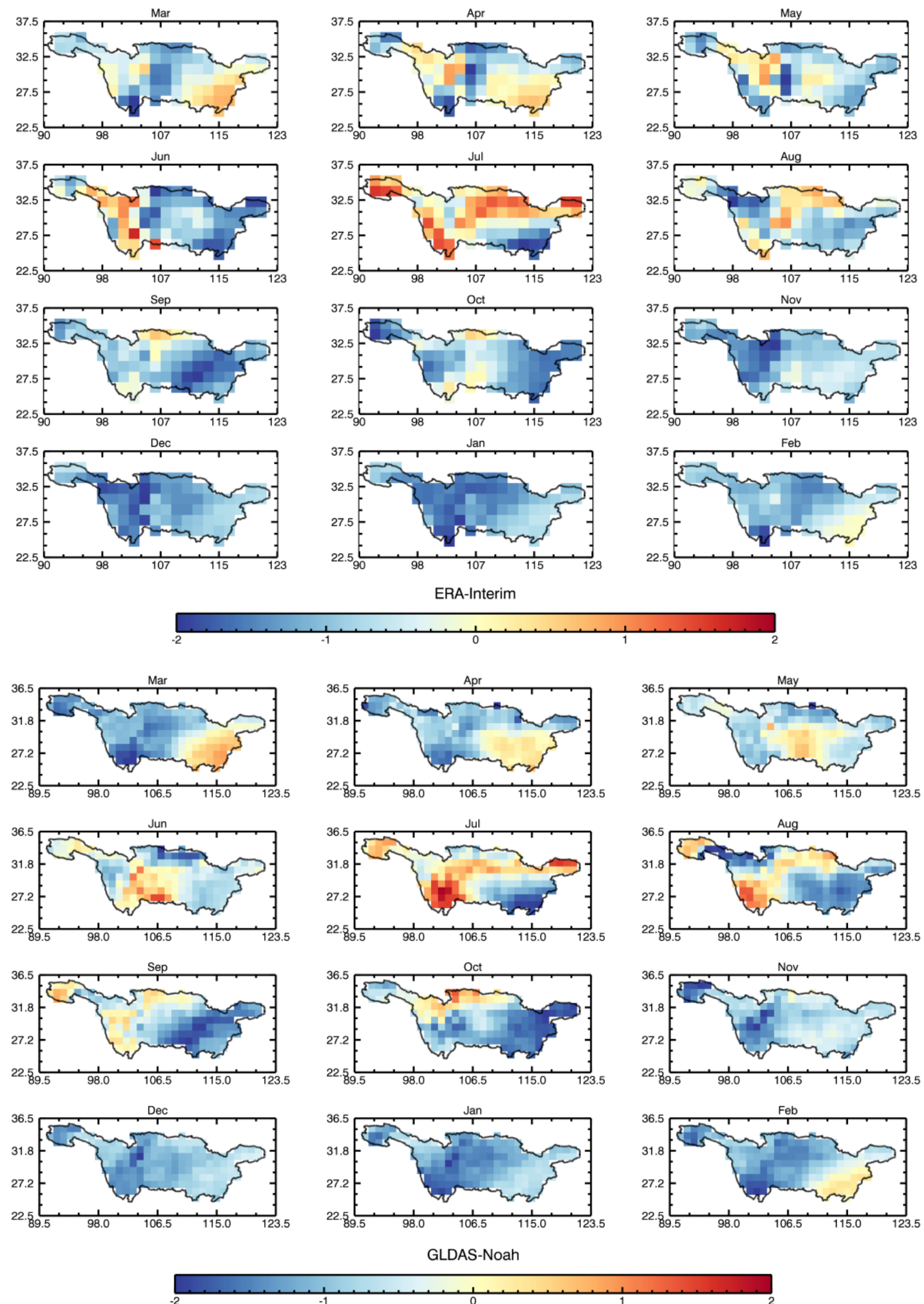

Fig. 6. Spatial patterns of monthly averaged TWSC annual standardized anomalies computed from ERA-Interim for the period January 1979 till December 2010 and from GLDAS-Noah for the periods January 1979 till December 1995 and January 1998 till December 2010. 

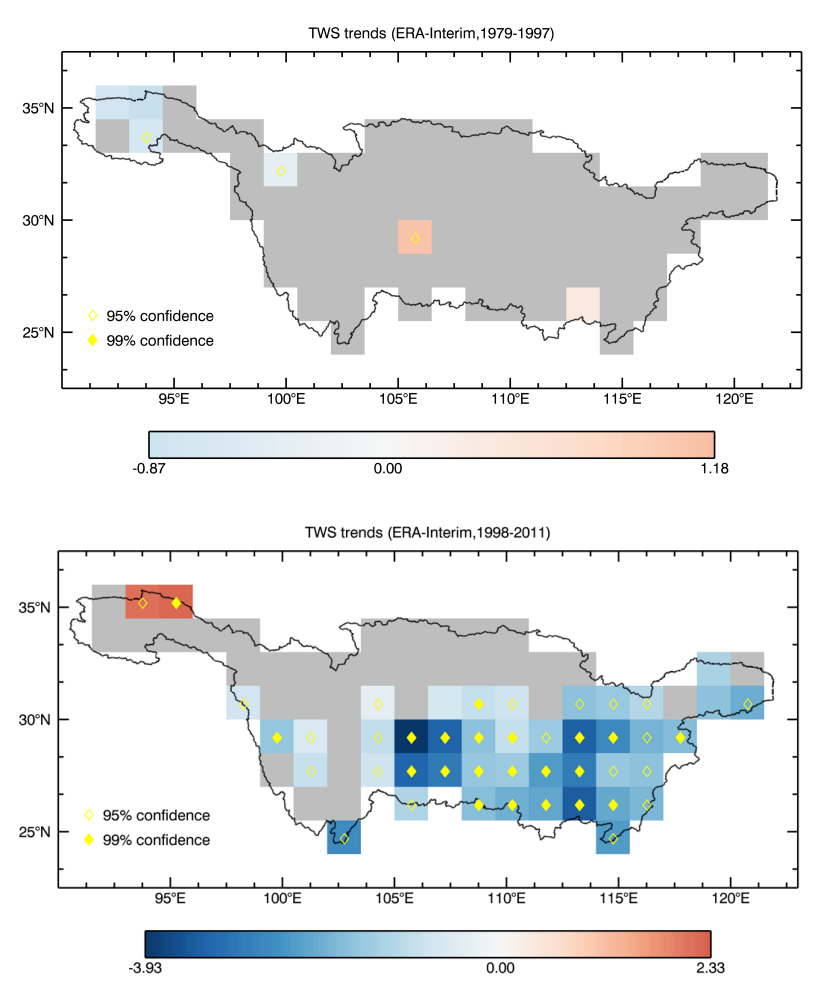

Fig. 7. ERA-Interim estimated TWS annual trends between 1979 and 1997, and between 1998 and 2010, in millimeters per year. Gray grids cells represent insignificant trends; cells with an empty diamond indicate the trend surpasses the $95 \%$ confidence level; cells with a filled diamond indicate the trend surpasses the $99 \%$ confidence level; others indicate the trend surpasses the $90 \%$ confidence level.

flood season. In 2007, the area around the Yangtze River suffered a severe drought again. In some places the water levels of the river dropped to their lowest levels since records began $142 \mathrm{yr}$ ago. The drought was also severe in large areas of the normally wet south. Reservoirs and rivers shrunk and supplies of drinking water fell to alarmingly low levels. However, he extreme drought of 2009/2010 over southwestern Yangtze (including Yunnan, Sichuan and Guizhou) is the driest meteorological event with the lowest percentage rainfall anomaly and the longest rain-free period occurring during a winter season (October-February) in the past 50 years, and also the severest one with the lowest percentage rainfall anomaly since 1880, as documented by Yang et al. (2012) (http://factsanddetails.com/china.php?itemid= $1879 \&$ catid $=10 \&$ subcatid $=64$ ).

Monthly standardized anomalies of precipitation from ERA-Interim, the GPCC, and PREC/L have been computed and compared to monthly standardized anomalies of TWS (not shown here) to examine possible correlation. The correlation between TWS anomalies from ERA-Interim and precipitation anomalies from ERA-Interim, the GPCC, and $\mathrm{PREC} / \mathrm{L}$ concerning the Yangtze basin is reasonably high in the wet season $(0.69,0.53$, and 0.49 , respectively), but much lower, especially for GPCC and PREC/L, in the dry season $(0.48,0.21$, and 0.25 , respectively). From a regional perspective, the middle and lower Yangtze reaches exhibited greater agreement between TWS from ERA-Interim and precipitation from the three datasets, than the upper Yangtze reaches did. The notable negative TWS anomalies in the middle and lower Yangtze reaches are in clear agreement with the significant decrease in precipitation seen in the ERA-Interim data in the past $6 \mathrm{yr}$; the GPCC and PREC/L data exhibit more gentle negative precipitation anomalies during this period and do not show any special difference to the prior period (not shown here). The differences can also be seen clearly in Fig. 3, where there is a clear downward shift for ERA-Interim relative to both the GPCC and PREC/L data in the past $6 \mathrm{yr}$. This shift matches the general decline in values relative to the GPCC data for the past decade, which may be caused by a too low sea surface temperature (SST) in the ERA-Interim dataset, or fewer stations in the GPCC archive in recent years (Simmons et al., 2010). PREC/L uses fewer gauging stations since the 1990s as well, thus it is difficult to assess the recent huge and sudden drop in the ERA-Interim figures only by comparing them to the GPCC and PREC/L data. However, the dramatic precipitation decrease in the middle and lower Yangtze reaches had been examined by Zhu et al. (2011, Fig. 2) over the past decade (2000-2008), and the rainfall anomalies based on a 160-station precipitation dataset of the last $58 \mathrm{yr}$ (1951-2008) dropped sharply from positive to negative values around 2004. This pattern of precipitation is consistent with the dramatic decrease of precipitation seen in ERA-Interim data, changing from positive to negative values since 2004 in the middle and lower Yangtze reaches (Fig. 3), suggesting that the recent drop in precipitation is most likely the biggest contributor to the massive decline in TWS in the middle and lower Yangtze reaches. Ding et al. (2008) pointed out that the recent change in the summer rainfall pattern in the Yangtze River is strongly related to the variability of the East Asian summer monsoon (EASM) through its moisture transport and supply. Zhu et al. (2011) stated that the eastward recession of the western Pacific subtropical high (WPSH) and the significant changes in the global SST are the main causes of the rainfall deficit in the Yangtze River basin since the year 2000. Yan et al. (2007) and Liu et al. (2007) documented that the intensification and westward shift of the WPSH and the easterly anomaly over the northern Indian Ocean are two key causes of the 2005-spring drought over southwestern China. The northward shift of the WPSH and the negative snow cover anomaly over the Tibetan Plateau are important contributors to the 2006-summer drought (Zhu and Gao, 2007; Li et al., 2009). The extreme drought event of 2009/2010 over southwestern China is associated with the westward extension of the WPSH brought about by the Arabian Sea cyclonic anomaly and the El Nino Modoki event during 2009/2010. 

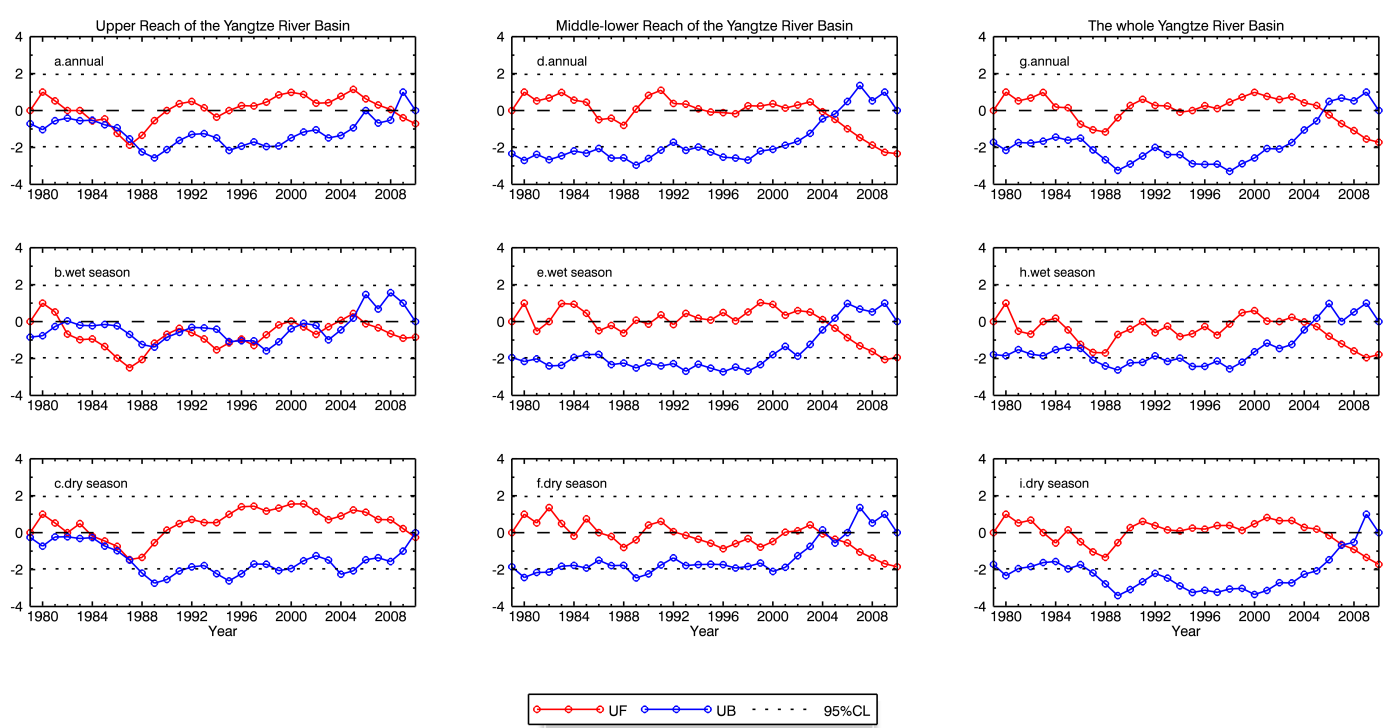

Fig. 8. The forward (UF, red) and backward (UB,blue) Mann-Kendall statistic rank series for TWS standardized anomalies, per year (a, d, $\mathbf{g}$ ), per wet season $(\mathbf{b}, \mathbf{e}, \mathbf{h})$, and per dry season $(\mathbf{c}, \mathbf{f}, \mathbf{i})$ during the period 1979 to 2010 for the upper reaches (a, b, c), the middle/lower reaches $(\mathbf{d}, \mathbf{e}, \mathbf{f})$ and the whole $(\mathbf{g}, \mathbf{h}, \mathbf{i})$ of the Yangtze River basin (the horizontally dotted lines represent the critical values corresponding to the $95 \%$ confidence level).
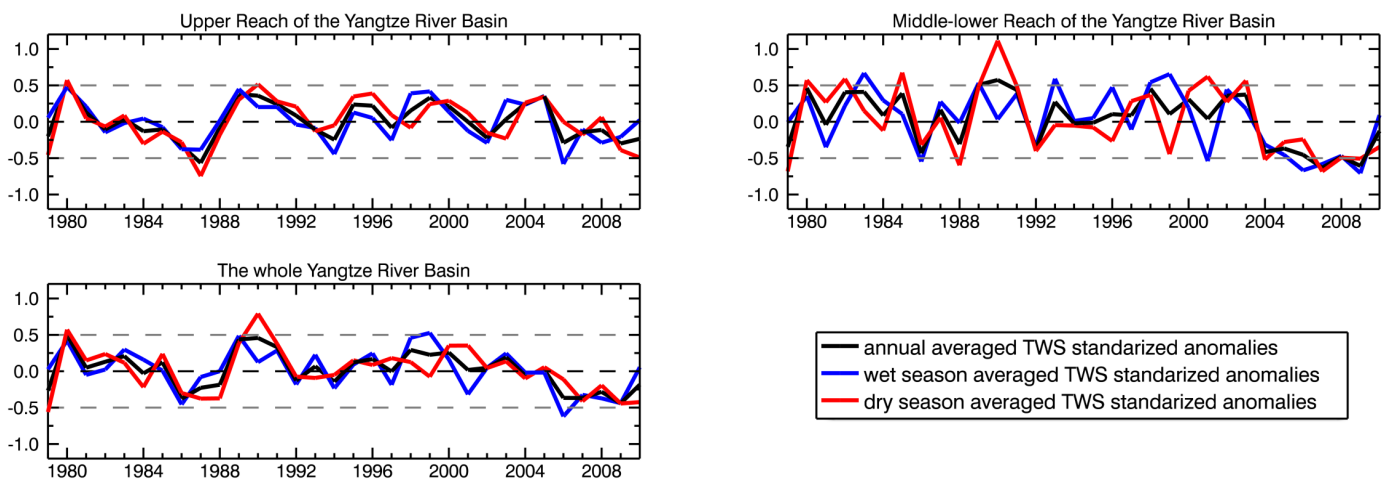

Fig. 9. The time series of the annual, wet season (May-October) and dry season averaged (November-April) TWS standardized anomalies for the upper Yangtze Reaches, the middle/lower Yangtze reaches and the whole Yangtze River Basin, respectively.

Since ERA-Interim TWS products do not include the impact of anthropogenic activity, such as the TGD and land cover change, in the model structure but rather in the assimilated observations, their effect on the regional climate in the Yangtze River basin is not obvious. However, some studies have tried to demonstrate the extent of human impact on the Yangtze River basin. For example, Dai et al. (2008) and Yang et al. (2010) show that the TGD reservoirs could have a direct impact on the intra-annual changes in the downstream Yangtze discharges, leading to a dumping of the seasonal variations in the Yangtze River discharge in the middle and lower reaches. Miller et al. (2005) and Wu et al. (2006) also documented that the land use change associated with the TGD would alter the regional pattern of precipitation, wind, and temperature. It could also impact the hydrologi- cal cycle of the river basin, and may lead to changes in the soil-climate interaction, which would probably alter the current dumping effect of soil wetness on the climate variability. As shown in Figs. 8 and 9, the consistent droughts in recent years and the operation of the TGD have occurred simultaneously. In 2003, the water level of the TGR reached $135 \mathrm{~m}$. Coincidently, in 2004, the driest period of the past $32 \mathrm{yr}$ began for the middle and lower Yangtze. Also, the whole basin suffered an abrupt change in 2006, when the TGR raised its water level from 135 to $156 \mathrm{~m}$. This coincidence is very striking and may imply the possible connection between the TGD and the consistent droughts in recent years, even though there has been no irrefutable evidence to prove that the TGR is responsible for the extremely driest period that has occurred in the past several years, as the TGD has only been 
in operation for a short period. Apart from the TGR, numerous other reservoirs within the Yangtze catchment together reached $200 \mathrm{~km}^{3}$ (Yang et al., 2005), more than five times the storage capacity of the TGR. The impact of these reservoirs on the TWS should not be ignored. The Yangtze basin has witnessed remarkable changes in land use and cover induced by high population density and rapid but uneven economic growth (Long et al., 2007; Yin et al., 2010). These changes might alter the soil properties and soil-climate interactions, probably having great influence on the TWS and runoff distribution. It should be pointed out that the ERAInterim TWS could contain significant uncertainties, as it relies heavily on satellite observations and modeling. Further investigation and analysis is needed to assess the significant impact of human activity on the TWS of the Yangtze River basin.

\section{Conclusions}

This study analyzes the spatial and temporal variations of the TWS in the Yangtze River basin during the period 1979 to 2010 based on ERA-Interim and GLDAS-Noah datasets. After comparison with field measurement data, ERA-Interim is found to perform better in the Yangtze River basin than GLDAS-Noah. Linear regression and the MK test have been used to detect trends and the significance of trends in TWS for each pixel in the whole basin. In addition, the MKS test has been used to detect transition points in the temporal series of the spatially averaged TWS annual standardized anomalies in the upper, middle/lower, and whole basin, respectively. We conclude that the TWS variations over the Yangtze River basin during the period 1979 to 2010 have the following characteristics:

- Most of the Yangtze basin exhibits the highest positive TWS anomalies during June-July, mainly due to the Meiyu rain event. This intensified rainfall not only results in very high positive TWS anomalies, but probably also leads to high runoff anomalies, causing floods across the basin.

- The Yangtze River basin is drying up, especially since the year 1998. The TWS variation is strongly correlated to the precipitation variation derived from ERA-Interim, the GPCC and PREC/L data, especially during the wet season and in the middle and lower reaches, suggesting the TWS variation is mainly controlled by precipitation.

- In the middle and lower Yangtze reaches, the TWS behavior changed abruptly and started to decrease in 2004. Coincidently, the TGR started impoundment in 2003. The year 2006 is detected as only transition point, initiating the TWS to suffer high negative anomalies, while the TGR raised its water level from 135 to $156 \mathrm{~m}$ that same year. Due to the short period of the TGD being in operation, it is hard to prove a link between the TGR and the consistent drought in recent years, but the coincidence suggests a possible connection.

- The past 6 yr period (2005-2010) was the driest period in terms of TWS in the Yangtze River basin (especially in the middle and lower Yangtze reaches) since 1979. This is mainly the result of a dramatic decrease in precipitation, which may also be influenced by human activity.

Acknowledgements. Ying Huang acknowledges the support received from the Chinese Scholarship Council (CSC). The authors are grateful for the advice given and the suggestions made by Xuebin Zhang and Kun Yang.

Edited by: D. Mazvimavi

\section{References}

Balsamo, G., Beljaars, A., Scipal, K., Viterbo, P., van den Hurk, B., Hirschi, M., and Betts, A. K.: A Revised Hydrology for the ECMWF Model: Verification from Field Site to Terrestrial Water Storage and Impact in the Integrated Forecast System, J. Hydrometeorol., 10, 623-643, doi:10.1175/2008jhm1068.1, 2009.

Berrisford, P., Dee, D., Poli, P., Brugge, R., Fielding, K., Fuentes, M., Kållberg, P., Kobayashi, S., Uppala, S., and Simmons, A.: The ERA-Interim archive, version 2.0, ERA report series 1, ECWMF, UK, 2011.

Bettadpur, S. and the CSR Level-2 Team: Assessment of GRACE mission performance and the RL05 gravity fields, Paper G31C02, AGU Fall Meeting, San Francisco, CA, 2012a.

Bettadpur, S. and the CSR Level-2 Team: Insights into the Earth System mass variability from CSR-RL05 GRACE gravity fields, Geophysical Research Abstracts, Vol. 14, EGU2012-6409, EGU General Assembly, 2012b.

Brunsell, N. A., Mechem, D. B., and Anderson, M. C.: Surface heterogeneity impacts on boundary layer dynamics via energy balance partitioning, Atmos. Chem. Phys., 11, 3403-3416, doi:10.5194/acp-11-3403-2011, 2011.

Burn, D. H. and Hag Elnur, M. A.: Detection of hydrologic trends and variability, J. Hydrol., 255, 107-122, doi:10.1016/S00221694(01)00514-5, 2002.

Chen, J. L., Rodell, M., Wilson, C. R., and Famiglietti, J. S.: Low degree spherical harmonic influences on Gravity Recovery and Climate Experiment (GRACE) water storage estimates, Geophys. Res. Lett., 32, L14405, doi:10.1029/2005g1022964, 2005.

Chen, J. L., Wilson, C. R., Tapley, B. D., Yang, Z. L., and Niu, G. Y.: 2005 drought event in the Amazon River basin as measured by GRACE and estimated by climate models, J. Geophys. Res., 114, B05404, doi:10.1029/2008jb006056, 2009.

Chen, M., Xie, P., Janowiak, J. E., and Arkin, P. A.: Global Land Precipitation: A 50-yr Monthly Analysis Based on Gauge Observations, Journal of Hydrometeorology, 3, 249-266, doi:10.1175/1525-7541(2002)003<0249: glpaym>2.0.co;2, 2002. 
Dai, Z., Du, J., Li, J., Li, W., and Chen, J.: Runoff characteristics of the Changjiang River during 2006: Effect of extreme drought and the impounding of the Three Gorges Dam, Geophys. Res. Lett., 35, L07406, doi:10.1029/2008g1033456, 2008.

Dee, D. P., Uppala, S. M., Simmons, A. J., Berrisford, P., Poli, P., Kobayashi, S., Andrae, U., Balmaseda, M. A., Balsamo, G., Bauer, P., Bechtold, P., Beljaars, A. C. M., van de Berg, L., Bidlot, J., Bormann, N., Delsol, C., Dragani, R., Fuentes, M., Geer, A. J., Haimberger, L., Healy, S. B., Hersbach, H., Hólm, E. V., Isaksen, L., Kållberg, P., Köhler, M., Matricardi, M., McNally, A. P., Monge-Sanz, B. M., Morcrette, J. J., Park, B. K., Peubey, C., de Rosnay, P., Tavolato, C., Thépaut, J. N., and Vitart, F.: The ERA-Interim reanalysis: configuration and performance of the data assimilation system, Q. J. Roy. Meteorol. Soc., 137, 553597, doi:10.1002/qj.828, 2011.

Ding, Y. H.: Summer monsoon rainfalls in China, J. Meteor. Soc. Jpn., 70, 373-396, 1992.

Ding, Y. H. and Chan, J. C. L.: The East Asian summer monsoon: an overview, Meteorol. Atmos. Phys., 89, 117-142, doi:10.1007/s00703-005-0125-z, 2005.

Ding, Y. H., Wang, Z., and Sun, Y.: Inter-decadal variation of the summer precipitation in East China and its association with decreasing Asian summer monsoon. Part I: Observed evidences, Int. J. Climatol., 28, 1139-1161, doi:10.1002/joc.1615, 2008.

Ding, Y. H., Sun, Y., Wang, Z., Zhu, Y., and Song, Y.: Inter-decadal variation of the summer precipitation in China and its association with decreasing Asian summer monsoon Part II: Possible causes, Int. J. Climatol., 29, 1926-1944, doi:10.1002/joc.1759, 2009.

Dirmeyer, P. A.: The terrestrial segment of soil moistureclimate coupling, Geophys. Res. Lett., 38, L16702, doi:10.1029/2011g1048268, 2011.

Dorigo, W. A., Scipal, K., Parinussa, R. M., Liu, Y. Y., Wagner, W., de Jeu, R. A. M., and Naeimi, V.: Error characterisation of global active and passive microwave soil moisture datasets, Hydrol. Earth Syst. Sci., 14, 2605-2616, doi:10.5194/hess-14-26052010, 2010.

Dorigo, W. A., Wagner, W., Hohensinn, R., Hahn, S., Paulik, C., Xaver, A., Gruber, A., Drusch, M., Mecklenburg, S., van Oevelen, P., Robock, A., and Jackson, T.: The International Soil Moisture Network: a data hosting facility for global in situ soil moisture measurements, Hydrol. Earth Syst. Sci., 15, 1675-1698, doi:10.5194/hess-15-1675-2011, 2011.

Dunne, T. : Field studies of hillslope flow processes, in: Hillslope Hydrology, edited by: Kirkby, M. J., Wiley-Interscience, New York, 227-293, 1978.

Entekhabi, D., Njoku, E. G., O’Neill, P. E., Kellogg, K. H., Crow, W. T., Edelstein, W. N., Entin, J. K., Goodman, S. D., Jackson, T. J., Johnson, J., Kimball, J., Piepmeier, J. R., Koster, R. D., Martin, N., McDonald, K. C., Moghaddam, M., Moran, S., Reichle, R., Shi, J. C., Spencer, M. W., Thurman, S. W., Leung, T., and Van Zyl, J.: The Soil Moisture Active Passive (SMAP) Mission, Proc. IEEE, 98, 704-716, doi:10.1109/jproc.2010.2043918, 2010.

Famiglietti, J. S.: Remote Sensing of Terrestrial Water Storage, Soil Moisture and Surface Waters, in: The State of the Planet: Frontiers and Challenges in Geophysics, Geophysical Monograph Series, 150, edited by: Sparks, R. S. J. and Hawkesworth, C. J., AGU, Washington, D. C., USA, 197-207, 2004.
Famiglietti, J. S., Ryu, D., Berg, A. A., Rodell, M., and Jackson, T. J.: Field observations of soil moisture variability across scales, Water Resour. Res., 44, W01423, doi:10.1029/2006wr005804, 2008.

Giorgi, F., Hurrell, J. W., Marinucci, M. R., and Beniston, M.: Elevation Dependency of the Surface Climate Change Signal: A Model Study, J. Climate, 10, 288-296, doi:10.1175/15200442(1997)010<0288:edotsc > 2.0.co;2, 1997.

Harvey, J. and Tang, L.: Analysis of the Global Precipitation Climatology Project Data for Four Global River Basins, GPCPReport, GPCP, University of Maryland, 2007.

Horton, R. E.: The role of infiltration in the hydrologic cycle, Trans. Am. Geophys. Union, 14, 446-460, 1933.

IPCC: Climate Change 2001: The Scientific Basis. Contribution of Working Group I to the Third Assessment Report of the Intergovernmental Panel on Climate Change, edited by: Houghton, J. T., Ding, Y., Griggs, D. J., Noguer, M., van der Linden, P. J., Dai, X., Maskell, K., and Johnson, C. A., Cambridge University Press, Cambridge, United Kingdom and New York, NY, USA, 881 pp., 2001.

Jung, M., Reichstein, M., Ciais, P., Seneviratne, S. I., Sheffield, J., Goulden, M. L., Bonan, G., Cescatti, A., Chen, J., de Jeu, R., Dolman, A. J., Eugster, W., Gerten, D., Gianelle, D., Gobron, N., Heinke, J., Kimball, J., Law, B. E., Montagnani, L., Mu, Q., Mueller, B., Oleson, K., Papale, D., Richardson, A. D., Roupsard, O., Running, S., Tomelleri, E., Viovy, N., Weber, U., Williams, C., Wood, E., Zaehle, S., and Zhang, K.: Recent decline in the global land evapotranspiration trend due to limited moisture supply, Nature, 467, 951-954, 2010.

Kendall, M. G.: Rank Correlation Measures, Charles Griffin, London, 1975.

Li, C., Yang, Z., and Wang, X.: Trends of Annual Natural Runoff in the Yellow River Basin, Water Int., 29, 447-454, doi:10.1080/02508060408691807, 2004.

Li, L. J., Zhang, L., Wang, H., Wang, J., Yang, J. W., Jiang, D. J., Li, J. Y., and Qin, D. Y.: Assessing the impact of climate variability and human activities on streamflow from the Wuding River basin in China, Hydrol. Process., 21, 3485-3491, doi:10.1002/hyp.6485, 2007.

Li, Y. H., Xu, H. M., and Liu, D.: Features of the extremely severe drought in the east of South-west China and anomalies of atmospheric circulation in summer 2006, Acta Meterol. Sin., 67, 122-132, 2009 (in Chinese).

Liu, Y., Zhao, E. X., Peng, G. F., and Yang, S. Q.: Severe drought in the early summer of 2005 in Yunnan and middle-high latitudes circulation, Arid. Meteor., 25, 32-37, 2007 (in Chinese).

Liu, Y. Y., Parinussa, R. M., Dorigo, W. A., De Jeu, R. A. M., Wagner, W., van Dijk, A. I. J. M., McCabe, M. F., and Evans, J. P.: Developing an improved soil moisture dataset by blending passive and active microwave satellite-based retrievals, Hydrol. Earth Syst. Sci., 15, 425-436, doi:10.5194/hess-15-425-2011, 2011.

Long, H., Heilig, G. K., Li, X., and Zhang, M.: Socio-economic development and land-use change: Analysis of rural housing land transition in the Transect of the Yangtse River, China, Land Use Policy, 24, 141-153, doi:10.1016/j.landusepol.2005.11.003, 2007.

Ma, Y., Menenti, M., Feddes, R., and Wang, J.: Analysis of the land surface heterogeneity and its impact on atmospheric variables and the aerodynamic and thermodynamic roughness lengths, J. 
Geophys. Res., 113, D08113, doi:10.1029/2007jd009124, 2008.

Mann, H. B.: Nonparametric Tests Against Trend, Econometrica, 13, 245-259, 1945.

Miller, N. L., Jin, J., and Tsang, C.-F.: Local climate sensitivity of the Three Gorges Dam, Geophys. Res. Lett., 32, L16704, doi:10.1029/2005g1022821, 2005.

Moraes, J. M., Pellegrino, G. Q., Ballester, M. V., Martinelli, L. A., Victoria, R. L., and Krusche, A. V.: Trends in Hydrological Parameters of a Southern Brazilian Watershed and its Relation to Human Induced Changes, Water Resour. Manage., 12, 295-311, doi:10.1023/a:1008048212420, 1998.

Niu, G. Y. and Yang, Z. L.: Assessing a land surface model's improvements with GRACE estimates, Geophys. Res. Lett., 33, L07401, doi:10.1029/2005g1025555, 2006.

Piao, S., Ciais, P., Huang, Y., Shen, Z., Peng, S., Li, J., Zhou, L., Liu, H., Ma, Y., Ding, Y., Friedlingstein, P., Liu, C., Tan, K., Yu, Y., Zhang, T., and Fang, J.: The impacts of climate change on water resources and agriculture in China, Nature, 467, 43-51, 2010.

Qian, W., Kang, H. S., and Lee, D. K.: Distribution of seasonal rainfall in the East Asian monsoon region, Theor. Appl. Climatol., 73, 151-168, doi:10.1007/s00704-002-0679-3, 2002.

Rodell, M., Famiglietti, J. S., Chen, J., Seneviratne, S. I., Viterbo, P., Holl, S., and Wilson, C. R.: Basin scale estimates of evapotranspiration using GRACE and other observations, Geophys. Res. Lett., 31, L20504, doi:10.1029/2004g1020873, 2004.

Rui, H.: README Document for Global Land Data Assimilation System Version 1 (GLDAS-1) Products,Goddard Earth Sciences Data and Information Services Center, NASA, USA, 2011.

Salama, M., Van der Velde, R., Zhong, L., Ma, Y., Ofwono, M., and $\mathrm{Su}, \mathrm{Z}$.: Decadal variations of land surface temperature anomalies observed over the Tibetan Plateau by the Special Sensor Microwave Imager (SSM/I) from 1987 to 2008, Climatic Change, 114, 769-781, doi:10.1007/s10584-012-0427-3, 2012.

Schneider, U., Becker, A., Meyer-Christoffer, A., Ziese, M., and Rudolf, B.: Global Precipitation Analysis Products of the GPCC, Global Precipitation Climatology Centre (GPCC), Deutscher Wetterdienst, Offenbach a. M., Germany, December, 2011.

Scipal, K., Holmes, T., de Jeu, R., Naeimi, V., and Wagner, W.: A possible solution for the problem of estimating the error structure of global soil moisture data sets, Geophys. Res. Lett., 35, L24403, doi:10.1029/2008g1035599, 2008.

Seneviratne, S. I., Viterbo, P., Lüthi, D., and Schär, C.: Inferring Changes in Terrestrial Water Storage Using ERA-40 Reanalysis Data: The Mississippi River Basin, J. Climate, 17, 2039-2057, doi:10.1175/1520-0442(2004)017<2039:icitws>2.0.co;2, 2004.

Seneviratne, S. I., Corti, T., Davin, E. L., Hirschi, M., Jaeger, E. B., Lehner, I., Orlowsky, B., and Teuling, A. J.: Investigating soil moisture-climate interactions in a changing climate: A review, Earth-Sci. Rev., 99, 125-161, doi:10.1016/j.earscirev.2010.02.004, 2010.

Simmons, A., Uppala, S., Dee, D., and Kobayashi, S.: ERA-Interim: New ECMWF reanalysis products from 1989 onwards, ECMWF Newsletter, 110, 26-35, 2006.

Simmons, A. J., Willett, K. M., Jones, P. D., Thorne, P. W., and Dee, D. P.: Low-frequency variations in surface atmospheric humidity, temperature, and precipitation: Inferences from reanalyses and monthly gridded observational data sets, J. Geophys. Res., 115, D01110, doi:10.1029/2009jd012442, 2010.
Sneyers, R.: Sur l'analyse statistique des séries d'observations, Secrétariat de l'Organisation Météorologique Mondiale, Genève, 1975.

Syed, T. H., Famiglietti, J. S., Rodell, M., Chen, J., and Wilson, C. R.: Analysis of terrestrial water storage changes from GRACE and GLDAS, Water Resour. Res., 44, W02433, doi:10.1029/2006wr005779, 2008.

Tapley, B. D., Bettadpur, S., Watkins, M., and Reigber, C.: The gravity recovery and climate experiment: Mission overview and early results, Geophys. Res. Lett., 31, L09607, doi:10.1029/2004g1019920, 2004a.

Tapley, B. D., Bettadpur, S., Ries, J. C., Thompson, P. F., and Watkins, M. M.: GRACE Measurements of Mass Variability in the Earth System, Science, 305, 503-505, doi:10.1126/science.1099192, 2004b.

van der Velde, R., Su, Z., and Ma, Y.: Impact of Soil Moisture Dynamics on ASAR $\sigma^{\circ}$ Signatures and Its Spatial Variability Observed over the Tibetan Plateau, Sensors, 8, 5479-5491, 2008.

Viterbo, P. and Beljaars, A. C. M.: An improved land surface parameterization scheme in the ECMWF model and its validation, J. Climate, 8, 2716-2748, 1995.

Wang, H. L., Liu, J., and Kuang, X. Y.: Comparison of Four Reanalysis Precipitation Datasets and Observation over the Middle Lower Reaches of the Yangtze River, Resources and Environment in the Yangtze Basin, 17, 703-711, 2008 (in Chinese).

Wei, J., Dirmeyer, P. A., Bosilovich, M. G., and Wu, R.: Water vapor sources for Yangtze River Valley rainfall: Climatology, variability, and implications for rainfall forecasting, J. Geophys. Res., 117, D05126, doi:10.1029/2011jd016902, 2012.

Wong, C. M., Williams, C. E., Pittock, J., Collier, U., and Schelle, P.: World's top 10 rivers at risk, WWF International, Gland, Switzerland, 2007.

Wu, L., Zhang, Q., and Jiang, Z.: Three Gorges Dam affects regional precipitation, Geophys. Res. Lett., 33, L13806, doi:10.1029/2006gl026780, 2006.

Yan, H. M., Duan, X., and Cheng, J. G. : Study on a severe drought event over Yunnan in spring 2005, J. Trop. Meteorol., 23, 300306, 2007 (in Chinese).

Yang, J., Gong, D., Wang, W., Hu, M., and Mao, R.: Extreme drought event of 2009/2010 over southwestern China, Meteorol. Atmos. Phys., 115, 173-184, doi:10.1007/s00703-011-01726, 2012.

Yang, S. L., Zhang, J., Zhu, J., Smith, J. P., Dai, S. B., Gao, A., and Li, P.: Impact of dams on Yangtze River sediment supply to the sea and delta intertidal wetland response, J. Geophys. Res., 110, F03006, doi:10.1029/2004jf000271, 2005.

Yang, S. L., Liu, Z., Dai, S. B., Gao, Z. X., Zhang, J., Wang, H. J., Luo, X. X., Wu, C. S., and Zhang, Z.: Temporal variations in water resources in the Yangtze River (Changjiang) over the Industrial Period based on reconstruction of missing monthly discharges, Water Resour. Res., 46, W10516, doi:10.1029/2009wr008589, 2010.

Yin, R., Xiang, Q., Xu, J., and Deng, X.: Modeling the Driving Forces of the Land Use and Land Cover Changes Along the Upper Yangtze River of China, Environ. Manage., 45, 454-465, doi:10.1007/s00267-009-9377-6, 2010.

Zaitchik, B. F., Rodell, M., and Olivera, F.: Evaluation of the Global Land Data Assimilation System using global river discharge data and a source-to-sink routing scheme, Water Resour. Res., 46, 
W06507, doi:10.1029/2009wr007811, 2010.

Zeng, N., Yoon, J. H., Mariotti, A., and Swenson, S.: Variability of Basin-Scale Terrestrial Water Storage from a PER Water Budget Method: The Amazon and the Mississippi, J. Climate, 21, 248265, doi:10.1175/2007jcli1639.1, 2008.

Zhang, J., Wu, L., and Dong, W.: Land-atmosphere coupling and summer climate variability over East Asia, J. Geophys. Res., 116, D05117, doi:10.1029/2010jd014714, 2011.

Zhong, L., Ma, Y., Salama, M., and Su, Z.: Assessment of vegetation dynamics and their response to variations in precipitation and temperature in the Tibetan Plateau, Climatic Change, 103, 519-535, doi:10.1007/s10584-009-9787-8, 2010.
Zhu, Y., Wang, H., Zhou, W., and Ma, J.: Recent changes in the summer precipitation pattern in East China and the background circulation, Clim. Dynam., 36, 1463-1473, doi:10.1007/s00382010-0852-9, 2011.

Zou, X. K. and Gao, H.: Analysis of severe drought and heat wave over the Sichuan Basin in the summer of 2006, Adv. Clim. Chang. Res., 3, 149-153, 2007 (in Chinese). 